\title{
Different stress modalities result in distinct steroid hormone responses by male rats
}

M.L. Andersen,

M. Bignotto,

R.B. Machado and S. Tufik

\author{
Departamento de Psicobiologia, Universidade Federal de São Paulo, \\ Escola Paulista de Medicina, São Paulo, SP, Brasil
}

\author{
Correspondence \\ M.L. Andersen \\ Departamento de Psicobiologia \\ EPM, UNIFESP \\ Rua Napoleão de Barros, 925 \\ 04024-002 São Paulo, SP \\ Brasil \\ Fax: +55-11-5572-5092 \\ E-mail: mandersen@sti.com.br \\ Presented at the III Congresso \\ de Integração em Biologia da \\ Reprodução, Ribeirão Preto, SP, \\ Brazil, April 12-15, 2003. \\ Research supported by Associação \\ Fundo de Incentivo à Psico- \\ farmacologia (AFIP) and FAPESP \\ (No. 01/04329-0 to M.L. Andersen \\ and CEPID \#98/14303-3 to S. Tufik).
}

Received July 14, 2003 Accepted February 10, 2004

\begin{abstract}
Since both paradoxical sleep deprivation (PSD) and stress alter male reproductive function, the purpose of the present study was to examine the influence of PSD and other stressors (restraint, electrical footshock, cold and forced swimming, $\mathrm{N}=10$ per group) on steroid hormones in adult Wistar male rats. Rats were submitted to chronic stress for four days. The stressors (footshock, cold and forced swimming) were applied twice a day, for periods of $1 \mathrm{~h}$ at 9:00 and 16:00 h. Restrained animals were maintained in plastic cylinders for $22 \mathrm{~h} /$ day whereas PSD was continuous. Hormone determination was measured by chemiluminescent enzyme immunoassay (testosterone), competitive immunoassay (progesterone) and by radioimmunoassay (corticosterone, estradiol, estrone). The findings indicate that PSD (13.7 ng/ $\mathrm{dl})$, footshock ( $31.7 \mathrm{ng} / \mathrm{dl})$ and cold $(35.2 \mathrm{ng} / \mathrm{dl})$ led to lower testosterone levels compared to the swimming ( $370.4 \mathrm{ng} / \mathrm{dl})$ and control (371.4 $\mathrm{ng} / \mathrm{dl}$ ) groups. However, progesterone levels were elevated in the footshock $(4.5 \mathrm{ng} / \mathrm{ml})$ and PSD $(5.4 \mathrm{ng} / \mathrm{ml})$ groups compared to control $(1.6 \mathrm{ng} / \mathrm{ml})$, swimming $(1.1 \mathrm{ng} / \mathrm{ml})$, cold $(2.3 \mathrm{ng} / \mathrm{ml})$, and restrained $(1.2 \mathrm{ng} / \mathrm{ml})$ animals. Estrone and estradiol levels were reduced in the PSD, footshock and restraint groups compared to the control, swimming and cold groups. A significant increase in corticosterone levels was found only in the PSD $(299.8 \mathrm{ng} / \mathrm{ml})$ and footshock $(169.6 \mathrm{ng} / \mathrm{ml})$ groups. These changes may be thought to be the full steroidal response to stress of significant intensity. Thus, the data suggest that different stress modalities result in distinct steroid hormone responses, with PSD and footshock being the most similar.
\end{abstract}

Key words

- Paradoxical sleep

deprivation

- Stress

- Testosterone

- Progesterone

- Estrogen

- Corticosterone

\section{Introduction}

Sleep loss, which is increasingly frequent due to life style patterns in developed countries, has been associated with an alteration in the regulation of the hypothalamic-pituitary-adrenal (HPA) axis, with stress hormone release and with rapid autonomic activation (1).

In animals, regardless of the method used, i.e., single platform, multiple platforms or modified multiple platforms, paradoxical sleep deprivation (PSD) results in altered peripheral evidence of stress, such as body 
weight loss, reduced thymus weight, and increased adrenal weight (2). In addition, increased basal and ACTH-stimulated corticosterone levels $(3,4)$ are also observed, indicating that these techniques are stressful and result in several alterations in catecholamine (5) and hormone levels (6-8) and in drug-induced behaviors (7-13).

A diversity of aversive stimuli applied to animal models on a short- or long-term basis have been used to investigate the response of the HPA and/or gonadal axis to stress $(14,15)$. Stress-related hormones are known to modulate male reproductive functions by interfering with the hypothalamic pituitary-gonadal axis. A consequent altered secretion of sex steroids $(15,16)$ and a significant decrease in both the production of maturing spermatids and testicular maturation have been described in rats submitted to immobilization stress (15).

Stress impairs gonadal function and lowers testosterone levels in male rats $(17,18)$; however, the neuroendocrine mechanisms responsible for testosterone suppression are poorly understood. Moreover, reduced testosterone levels are also observed after PSD periods in contrast to a marked presence of genital reflexes such as in penile erection and ejaculation in adult and old rats $(6,13)$. Furthermore, PSD also alters progesterone (6-8) as well as estrogen (Andersen ML, Bignotto $\mathrm{M}$ and Tufik S, unpublished data) in male rats. However, the association between these hormones and stress has not been well documented.

On the basis of these considerations, the purpose of the present study was to examine the influence of PSD and other stressors (restraint, electrical footshock, cold, and forced swimming) on steroid hormone levels in adult male rats.

\section{Material and Methods}

\section{Subjects}

Sixty male Wistar rats bred in our facili- ties, aged 3 months, were used in this experiment. Before applying the stressors, rats were allowed to move freely in cages under conditions of alternating light (7:00 to $19: 00 \mathrm{~h})$ and darkness (19:00 to 7:00 h) and at room temperature of $22 \pm 1^{\circ} \mathrm{C}$. Laboratory chow and water were provided ad libitum. All procedures used in the present study complied with the Guide for the Care and Use of Laboratory Animals and the experimental protocol was approved by the Ethics Committee of UNIFESP (CEP \#N064/99).

\section{Experimental procedure}

The animals were assigned randomly to stressed or control groups of 10 rats each. The control group consisted of animals that remained inside their home cages and were not manipulated, except for routine cage cleaning. Experimental animals were submitted to one modality of chronic stress applied repeatedly for four days as described below and according to a previous study by Tufik et al. (19).

Swimming. The rats were introduced individually inside a $23-\mathrm{cm}$-high container filled with water at $22-24^{\circ} \mathrm{C}$ and swam twice a day for $1 \mathrm{~h}$ each time. After the session, they were removed, allowed to dry and returned to their home cages. The experiment was carried out at 9:00 and 16:00 h.

Restraint. The animals were maintained in plastic cylinders $(21 \mathrm{~cm}$ in length $\mathrm{x} 6 \mathrm{~cm}$ in diameter) for $22 \mathrm{~h} /$ day. In the intervening hours twice a day (1-h periods), the rats were allowed to move freely in their cages to eat and drink at 9:00 and 16:00 h.

Footshock. The animals were placed individually in the compartments $(14 \times 25 \times 28$ $\mathrm{cm})$ of an acrylic box containing an electrified grid on the floor, through which the shocks were delivered. Shock intensity was $2 \mathrm{~mA}$, lasting $0.25 \mathrm{~s}$ at intervals of approximately $15 \mathrm{~s}$. Four to six shocks were delivered per minute with a variable inter-shock interval, which was changed every 5 min in 
order to prevent anticipation by the animal. The shocks were applied twice a day for periods of $1 \mathrm{~h}$ at 9:00 and 16:00 $\mathrm{h}$.

Cold. The animals were placed individually in a cold chamber at $4^{\circ} \mathrm{C}$, inside a wiremesh cage, twice a day, for periods of $1 \mathrm{~h}$ at 9:00 and 16:00 $\mathrm{h}$.

Paradoxical sleep deprivation. The PSD method consisted of placing 10 rats in a tiled water tank $(123 \times 44 \times 44 \mathrm{~cm})$ for $96 \mathrm{~h}$. The tank contained 14 platforms $(6.5 \mathrm{~cm}$ in diameter) immersed in water up to $1 \mathrm{~cm}$ from their upper surface. The rats could thus move around inside the tank by jumping from one platform to another. When they reached the paradoxical phase of sleep, muscle atonia set in and they fell into the water and woke. Control rats lodged in the home cage show normal sleep patterns. During PSD, the animals had food and fresh water available ad libitum. Throughout the study, the experimental room was maintained under controlled temperature $\left(23 \pm 1^{\circ} \mathrm{C}\right)$ and a light-dark cycle (lights on at 7:00 and off at 19:00 h). Under these conditions, this procedure caused a complete loss of PSD in each of the four days (20).

\section{Blood sampling and hormone analyses}

All rats (control or stressed) were sacrificed immediately after the last morning application of stress (4-day period) at the same time by decapitation between 9:00 and 11:00 $\mathrm{h}$ with a minimum of disturbance in an adjacent room. Blood samples were collected and centrifuged at $1575 \mathrm{~g}$ for $10 \mathrm{~min}$ and frozen at $-20^{\circ} \mathrm{C}$ until assayed for hormone levels. All samples for hormone measurement were always quantified in the same assay and the intra-assay coefficients are given in parentheses. Testosterone concentration $(6.7 \%)$ was measured by chemiluminescent enzyme immunoassay (Immulite Automated Analyses - Diagnostic Products Corporation, Los Angeles, CA, USA). The detection threshold was $10 \mathrm{ng} / \mathrm{dl}$. Progeste- rone $(6.5 \%)$ was measured by competitive immunoassay (TOSOH Corporation, Tokyo, Japan) and the minimal detectable concentration was $0.1 \mathrm{ng} / \mathrm{ml}$. For corticosterone determination, trunk blood was collected into pre-cooled plastic vials containing $0.2 \mathrm{ml}$ of a $10 \%$ EDTA solution and centrifuged at $1575 \mathrm{~g}$ for $10 \mathrm{~min}$ at $4^{\circ} \mathrm{C}$. Plasma was extracted, stored in plastic tubes and frozen until the assays were performed. Corticosterone $(7.1 \%)$ levels were assayed by a double antibody radioimmunoassay method specific for rats and mice using a commercial kit (ICN Biomedicals, Costa Mesa, CA, USA). The sensitivity of the assay is $0.25 \mathrm{ng} / \mathrm{ml}$. Estradiol (4.9\%; Diagnostic Products Co., Los Angeles, CA, USA) and estrone (11.1\%; Diagnostic Systems Laboratories, Inc., Webster, TX, USA) were assayed by radioimmunoassay. The minimum detection limit is 1.4 and $1.2 \mathrm{pg} / \mathrm{ml}$, respectively. Duplicate serum aliquots for all hormone analyses were used. These assays are routinely performed in our hormone laboratory.

\section{Statistical analysis}

Data are reported as means \pm SEM and were analyzed statistically by one-way ANOVA. Groups were compared by the post hoc Tukey test. The level of significance was set at $\mathrm{P}<0.05$.

\section{Results}

\section{Changes in serum hormones after different chronic stressors}

The testosterone values are shown in Figure 1A. Statistical evaluation of the data revealed a difference among groups $\left[\mathrm{F}_{(5,55)}=\right.$ 10.29; $\mathrm{P}<0.0001]$. The post hoc Tukey test showed that four days of stress significantly reduced testosterone levels in the PSD $(\mathrm{P}<$ $0.001)$, footshock $(\mathrm{P}<0.001)$ and cold $(\mathrm{P}<$ $0.001)$ groups when compared with the control and swimming groups. Restraint stress 
Figure 1. Serum hormone levels of stressed rats. Data are reported as means \pm SEM for 10 rats in each group of serum testosterone (ng/dl, panel A), progesterone $(\mathrm{ng} / \mathrm{ml}$, panel B), estrone $(\mathrm{pg} / \mathrm{ml}$, panel C) and estradiol (pg/ml, panel D). Rat groups were as follows: non-stressed (control), swimming (SW), paradoxical sleep deprivation (PSD), footshock (FS), cold exposure, and restraint $(R) .{ }^{*} P<0.001$ compared to control and swimming, $\# P<0.01$ compared to the cold and immobilized groups, and $+P<0.01$ compared to the cold group (ANOVA test). did not affect the levels of this hormone.

Analysis of progesterone levels revealed significant main effects among groups $\left(\mathrm{F}_{(5,55)}\right.$ $=8.87 ; \mathrm{P}<0.0001)$. Chronic stress produced a significant increase in progesterone in the footshock $(\mathrm{P}<0.01)$ and PSD $(\mathrm{P}<0.001)$ groups compared to the control $(\mathrm{P}<0.01)$, swimming $(\mathrm{P}<0.001)$, cold $(\mathrm{P}<0.01)$ and restraint $(\mathrm{P}<0.001)$ groups, as illustrated in Figure 1B.

Estrone (Figure 1C) and estradiol (Figure

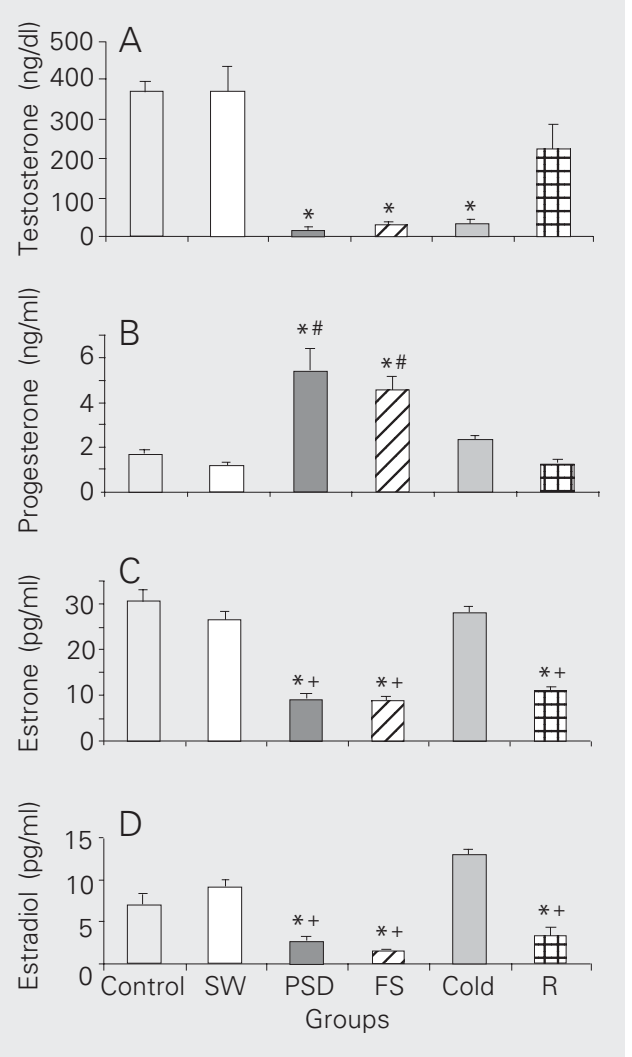

Figure 2. Corticosterone levels in stressed rats. Plasma levels of corticosterone $(\mathrm{ng} / \mathrm{ml})$ in animals maintained in their home cages (control) or submitted to swimming (SW), paradoxical sleep deprivation (PSD), footshock (FS), cold, or restraint (R). Data are reported as means \pm SEM for 10 rats in each group. ${ }^{*} P<0.0001$ and ${ }^{*} P<0.03$ compared to control and swimming, $\# P<0.001$ compared to cold and immobilized groups, and $+\mathrm{P}<0.01$ compared to footshock (ANOVA test).
1D) levels were significantly different in the five groups studied $\left(\mathrm{F}_{(5,55)}=37.08 ; \mathrm{P}<0.0001\right.$ and $\mathrm{F}_{(5,55)}=22.53 ; \mathrm{P}<0.0001$, respectively). The hormone levels were reduced in the PSD, footshock and restraint groups compared with the control, swimming and cold groups $(\mathrm{P}<0.01)$.

As shown in Figure 2, the ANOVA test $\left(F_{(5,55)}=13.41 ; P<0.00001\right)$ for corticosterone levels revealed the occurrence of a significant effect in response to stress. Statistical analysis by the Tukey test revealed that the PSD groups differed from the home cage and swimming ( $\mathrm{P}<0.0001)$, cold and restrained $(\mathrm{P}<0.001)$ and the footshock groups $(\mathrm{P}<0.01)$. Corticosterone levels were higher in the footshock group compared with the control and swimming groups $(\mathrm{P}<0.03)$.

\section{Discussion}

The purpose of the present study was to determine whether different kinds of stress would have the same effects on the levels of steroid hormones as previously found in PSD rats (6-8). Each kind of stress promotes different changes in each of the hormone levels. While PSD, footshock and cold led to lower testosterone levels, progesterone levels were elevated by footshock and PSD. Furthermore, estrone and estradiol levels were reduced by PSD, footshock and restraint. An overview of the results obtained indicates that different stress modalities result in distinct steroid hormone responses, with PSD and footshock being the most similar.

Some factors appear to be important to understand these variations in stress effects. First, the pattern of change depends on the nature of the stressful experience and the coping strategies mobilized to manage the situation. For instance, it has been suggested that swimming, if considered an exercise, actually results in a short-lasting reduction in serum testosterone levels in men; however, these levels return to basal values during or shortly after finishing the exercise 
$(21,22)$. The absence of significant changes in hormonal levels observed in the group submitted to forced swimming seems to confirm this suggestion. Second, stress effects vary in their time course and duration. Some important differences in responses emerge only with chronic stimulation, whereas other effects arise after intermittent stimulation. In fact, according to López-Calderón (23), rats subjected to chronic restraint for up to 4 consecutive days show reduced circulating levels of testosterone, whereas we subjected the animals to $22 \mathrm{~h}$ /day also for 4 consecutive days.

It has been suggested that stress-induced lower testosterone levels are mediated by luteinizing hormone (LH) (24). The precise mechanism of the inhibitory effect of prolonged stress on testosterone, however, is not yet fully understood since the alterations in androgenic response are not always associated with altered LH levels $(15,25)$. The lack of concurrent significant changes in $\mathrm{LH}$ levels implies that LH may not be involved in the testosterone response (26), suggesting that a testosterone depressor mechanism may involve other processes.

Gonadal steroid hormones regulate various neuroendocrine events including sexual behaviors by acting on the central nervous system (27). In males, testosterone exerts motivational effects necessary for the display of male sexual behavior (28). The suppression of testosterone has been attributed to increased levels of corticosteroids as part of the stress response. Increased corticosteroid levels are used as an index of stress (29). Palma et al. (30) studying acute stress modalities for $1 \mathrm{~h}$ reported that footshock induced the greatest adrenocorticotropin $(\mathrm{ACTH})$ response, while restraint and PSD resulted in higher levels than cold stress. Animals exposed to cold, in contrast, exhibited the highest corticosterone levels compared to the other stressors.

It has been proposed that higher corticosteroid levels may suppress gonadotropins
(31) and directly suppress testicular functions (32). In 1997, Fadda and Fratta (33) reported that rats exposed to $72 \mathrm{~h}$ of PSD showed a marked increase in corticotropinreleasing factor (CRF) levels in striatum, limbic and pituitary areas, whereas the hypothalamic CRF content was reduced. These results indicate that increased CRF release could stimulate corticosterone secretion, indicating that PSD is a stressful event.

The decreased serum testosterone, estradiol and estrone levels in the footshock and PSD groups were associated with marked increases in progesterone. Andersen et al. (6-8) showed that the decreased levels of testosterone observed could not be considered to be as the main factor predominating over the sexual behavior observed in the groups studied.

These results raise several questions concerning the origin of this increased progesterone and its role in stressed animals. Studies indicate that the adrenal cortex of the rat is able to synthesize and secrete significant amounts of progesterone $(34,35)$. Thus, the increased levels of progesterone could be a response to higher adrenal weight induced by the well-established stressor method of PSD (4). Increased adrenal weight of animals submitted to PSD may reflect a hyperfunctioning of the glands triggered by this stress and could explain, in part, the increased levels of progesterone in rats exposed to PSD and footshock. The increase in ACTH produced by stress may be responsible for the increase in progesterone as well as in corticosterone levels, since ACTH has been shown to stimulate adrenal progesterone production $(35,36)$.

Estrone and estradiol levels were decreased in the PSD, footshock and restraint groups. In addition to testosterone, Leydig cells also secrete small amounts of estradiol and estrone; however, synthesis in peripheral tissues is the main factor responsible for their circulating levels. Testosterone is the substrate for the synthesis of these estrogens 
and therefore any alteration of its concentration may also alter the secretion of these estrogens. Indeed, footshock and PSD produced a marked decrease in estrone and estradiol levels compared to home cage, cold and swimming animals. Estrogen appears to exert effects at multiple sites within putative HPA axis control pathways, even though most of the relevant neuronal populations do not contain genomic receptors for this gonadal steroid. Furthermore, the pattern of estrogen action also differs between an emotional and a physical stressor (37).

Finally, it is necessary to point-out that corticosterone level determinations represent an important parameter for the comparative purpose of the present study. Since it is methodologically difficult to design two or more conditions with equivalent stress intensities, corticosterone dosages may rank them. As depicted in Figure 2, significant increases in the levels of this hormone were found only in the PSD and footshock groups. In both cases, a decrease in testosterone, estradiol and estrone and an increase in pro- gesterone levels were observed. These changes may be thought to be the full steroidal response to stresses of significant intensities. They seem to be an adjustment for sexual activity restriction, since such activities are incompatible with dangerous or extremely aversive situations. The occurrence of one or two changes in these hormones, on the other hand, seems to be an effect of low intensity or short-lasting stresses or evoked by the different qualities of such stresses. In fact, long-lasting sleep deprivation may occur in overcrowded rats and decreased fertility is one mechanism of population density control. Swimming, however, is an eventual and short-lasting incident in a rat's life that does not require reduction of sexual activity.

\section{Acknowledgments}

The authors would like to express their thanks to Waldemarks Leite, Marilde Costa, Tome Pimentel, and Júlio Nascimento for assistance during the project.

\section{References}

1. Cauter EV (2000). Sleep loss, jet lag, and shift work. In: Fink G (Editor), Encyclopedia of Stress. Vol. 1. Academic Press, San Diego, CA, USA, 447-448.

2. Coenen AML \& Van Luijtelaar ELJM (1985). Stress induced by three procedures of deprivation of paradoxical sleep. Physiology and Behavior, 35: 501-504.

3. Patchev V, Felszeghy K \& Korányi L (1991). Neuroendocrine and neurochemical consequences of long-term sleep deprivation in rats: similarities to some features of depression. Homeostasis, 33: 97108.

4. Suchecki D, Tiba PA \& Tufik S (2002). Paradoxical sleep deprivation facilitates subsequent corticosterone response to a mild stressor in rats. Neuroscience Letters, 320: 45-48.

5. Farooqui SM, Brock JW \& Zhou J (1996). Changes in monoamines and their metabolite concentrations in REM sleep-deprived rat forebrain nuclei. Pharmacology, Biochemistry and Behavior, 54: 385391.

6. Andersen ML, Bignotto M, Machado RB \& Tufik S (2002). Does sleep deprivation and cocaine induce penile erection and ejaculation in old rats? Addiction Biology, 7: 285-290.

7. Andersen ML, Bignotto M \& Tufik S (2003). Influence of paradoxical sleep deprivation and cocaine on development of spontaneous penile reflexes in rats of different ages. Brain Research, 968: 130138.

8. Andersen ML, Bignotto M \& Tufik S (2003). Facilitation of ejaculation after methamphetamine administration in paradoxical sleep deprived rats. Brain Research, 978: 31-37.

9. Tufik S, Lindsey CJ \& Carlini EA (1978). Does REM sleep deprivation induce a supersensitivity of dopaminergic receptors in the rat brain? Pharmacology, 16: 95-108.

10. Andersen ML, Palma BD, Rueda AD \& Tufik S (2000). The effects of acute cocaine administration in paradoxical sleep-deprived rats. Addiction Biology, 5: 417-420.

11. Andersen ML \& Tufik $S$ (2002). Distinct effects of paradoxical sleep deprivation and cocaine administration on sexual behavior in male rats. Addiction Biology, 7: 251-253.

12. Andersen ML, Bignotto M \& Tufik S (2003). Cocaine-induced genital reflexes during paradoxical sleep deprivation and recovery. Physiology and Behavior, 78: 255-259.

13. Andersen ML, Bignotto M, Papale LA \& Tufik S (2004). Age-related effects of genital reflexes induced by paradoxical sleep deprivation and cocaine in rats. Experimental Gerontology, 39: 233-237. 
14. Almeida AS, Petenusci SO, Anselmo-Franci JA, Rosa-e-Silva AAM \& Carvalho TLL (1998). Chronic intermittent immobilization of male rats throughout sexual development: a stress protocol. Brazilian Journal of Medical and Biological Research, 31: 1443-1448.

15. Almeida AS, Petenusci SO, France JA, Rosa-e-Silva AAM \& Carvalho TLL (2000). Chronic immobilization-induced stress increases plasma testosterone and delays testicular maturation in pubertal rats. Andrologia, 32: 7-11.

16. Knol BW (1991). Stress and the endocrine hypothalamus pituitarytestis system: a review. Veterinary Quarterly, 13: 104-114.

17. Rose RM (1985). Psychoendocrinology. In: William RH (Editor), Textbook of Endocrinology. WB Saunders, Philadelphia, PA, USA, 653-681.

18. Akibami MA \& Mann DR (1996). Mechanism of the stress-induced attenuation of the testicular response to gonadotropin: possible involvement of testicular opioids, a pertussis toxin-sensitive Gprotein, and phosphodiesterase. Journal of Andrology, 17: 10-16.

19. Tufik S, Luca Nathan C, Neumann B, Hipolide DC, Lobo LL, Medeiros R, Troncone RPT, Braz S \& Suchecki D (1995). Effects of stress on drug-induced yawning: constant vs intermittent stress. Physiology and Behavior, 58: 181-184.

20. Machado RB, Hipolide DC, Benedito-Silva AA \& Tufik S (2004). Sleep deprivation induced by modified multiple platform technique: quantification of sleep loss and recovery. Brain Research (in press).

21. Cumming DC, Wall SR, Quinney HA \& Belcastro NA (1987). Decrease in serum testosterone levels with maximal intensity swimming exercise in trained male and female swimmers. Endocrine Research, 13: 31-41.

22. Tyndall GL, Kobe RW \& Houmard JA (1996). Cortisol, testosterone, and insulin action during intense swimming training in humans. European Journal of Applied Physiology, 73: 61-65.

23. López-Calderón A, Ariznavarreta C, González-Quijano MI, Tresguerres JA \& Calderón MD (1991). Stress induced changes in testis function. Journal of Steroid Biochemistry and Molecular Biology, 40: 473-479.

24. Demura R, Suzuki T, Nakamura S, Komatsu H, Odagiri E \& Demura $H$ (1989). Effect of immobilization stress on testosterone and inhibin in male rats. Journal of Andrology, 10: 210-213.

25. Orr ET, Taylor MF, Bhattacharya AK, Collins DC \& Mann DR (1994). Acute immobilization stress disrupts testicular steroidogenesis in adult male rats by inhibiting the activities of $17 \alpha$-hydroxylase and 17,20-lyase without affecting the binding of $\mathrm{LH} / \mathrm{hCG}$ receptors.
Journal of Andrology, 15: 302-308.

26. Elman I \& Breier A (1997). Effects of acute metabolic stress on plasma progesterone and testosterone in male subjects: relationship to pituitary-adrenocortical axis activation. Life Sciences, 61: 1705-1712.

27. Nomura M, Durbak L, Chan J, Smithies O, Gustafsson JA, Korach KS, Pfaff DW \& Ogawa S (2002). Genotype/age interactions on aggressive behavior in gonadally intact estrogen receptor $\beta$ knockout (ßERKO) male mice. Hormones and Behavior, 41: 288-296.

28. Roselli CE \& Chambers K (1999). Sex differences in male-typical copulatory behaviors in response to androgen and estrogen treatment in rats. Neuroendocrinology, 69: 290-298.

29. DeVries AC (2002). Interaction among social environment, the hypothalamic-pituitary-adrenal axis, and behavior. Hormones and Behavior, 41: 405-413.

30. Palma BD, Suchecki D \& Tufik S (2000). Differential effects of acute cold and footshock on the sleep of rats. Brain Research, 861: 97104.

31. Ringstrom SJ \& Schwartz NB (1987). Differential effect of glucocorticoids on synthesis and secretion of luteinizing hormone (LH) and follicle-stimulating hormone (FSH). Journal of Steroid Biochemistry, 27: 625-630.

32. Sapolsky RM (1985). Stress-induced suppression of testicular function in the wild baboon: role of glucocorticoids. Endocrinology, 116 2273-2278

33. Fadda P \& Fratta W (1997). Stress-induced sleep deprivation modifies corticotropin releasing factor (CRF) levels and CRF binding in rat brain and pituitary. Pharmacological Research, 35: 443-446.

34. Kalra PS \& Kalra SP (1977). Circadian periodicities of serum androgens, progesterone, gonadotropins and luteinizing hormone-releasing hormone in male rats: the effects of hypothalamic deafferentation, castration and adrenalectomy. Endocrinology, 101: 1821-1827.

35. Resko JA (1969). Endocrine control of adrenal progesterone secretion in the ovariectomized 35. Science, 164: 71-72.

36. Carroll JA, Willard ST, Bruner BL, McArthur NH \& Welsh THJ (1996). Mifespristone modulation of $\mathrm{ACTH}$ and $\mathrm{CRH}$ regulation of bovine adrenocorticosteroidogenesis in vitro. Domestic Animal Endocrinology, 13: 339-349.

37. Dayas CV, Xu Y, Buller KM \& Day TA (2000). Effects of chronic oestrogen replacement on stress-induced activation of hypothalamic-pituitary-adrenal axis control pathways. Journal of Neuroendocrinology, 12: 784-794. 